\title{
(6) OPEN ACCESS Effectiveness of workplace interventions in the
prevention of upper extremity musculoskeletal
disorders and symptoms: an update of the evidence
}

\author{
D Van Eerd, ${ }^{1,2}$ C Munhall, ${ }^{1}$ E Irvin, ${ }^{1}$ D Rempel, ${ }^{3}$ S Brewer, ${ }^{4}$ A J van der Beek, ${ }^{5}$ \\ J T Dennerlein, ${ }^{5,6}$ J Tullar, ${ }^{7}$ K Skivington, ${ }^{1,8}{ }^{C}$ Pinion, ${ }^{4}$ B Amick ${ }^{1,9}$
}

\begin{abstract}
- Additional material is published online only. To view please visit the journal online (http://dx.doi.org/10.1136/ oemed-2015-102992)

For numbered affiliations see end of article.
\end{abstract}

\section{Correspondence to} $D$ Van Eerd, Institute for Work \& Health, 481 University Ave, Suite 800, Toronto, Ontario, Canada M5G 2E9; dvaneerd@iwh.on.ca

Received 31 March 2015 Revised 18 September 2015 Accepted 27 September 2015 Published Online First 9 November 2015

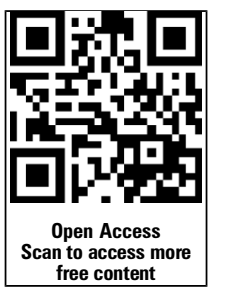

CrossMark

To cite: Van Eerd $D_{\text {, }}$ Munhall C, Irvin E, et al. Occup Environ Med 2016;73:62-70.

\section{ABSTRACT}

The burden of disabling musculoskeletal pain and injuries (musculoskeletal disorders, MSDs) arising from work-related causes in many workplaces remains substantial. There is little consensus on the most appropriate interventions for MSDs. Our objective was to update a systematic review of workplace-based interventions for preventing and managing upper extremity MSD (UEMSD). We followed a systematic review process developed by the Institute for Work \& Health and an adapted best evidence synthesis. 6 electronic databases were searched (January 2008 until April 2013 inclusive) yielding 9909 non-duplicate references. 26 high-quality and medium-quality studies relevant to our research question were combined with 35 from the original review to synthesise the evidence on 30 different intervention categories. There was strong evidence for one intervention category, resistance training, leading to the recommendation: Implementing a workplace-based resistance training exercise programme can help prevent and manage UEMSD and symptoms. The synthesis also revealed moderate evidence for stretching programmes, mouse use feedback and forearm supports in preventing UEMSD or symptoms. There was also moderate evidence for no benefit for EMG biofeedback, job stress management training, and office workstation adjustment for UEMSD and symptoms. Messages are proposed for both these and other intervention categories.

\section{INTRODUCTION}

Work-related musculoskeletal disorders (MSDs) are a constellation of painful disorders of muscles, tendons, joints and nerves which can affect all body parts, although the neck, upper limb and back are the most common areas. ${ }^{12}$ Overall workrelated MSDs account for 29\% of all US workplace injuries. $^{2}$ In Canada, MSDs account for between $40 \%$ and $60 \%$ of lost-time claims since $2000 .^{3-6}$ In Canada and the USA, upper extremity MSDs (UEMSDs) and low back pain are the leading causes of disabling work-related injuries. ${ }^{2-6}$ In Europe, UEMSDs and low back pain are considered to be an increasing and significant health problem, making up approximately 39\% of occupational diseases. ${ }^{1}$ Recent attention and studies suggest that MSDs are considered a growing problem in the developing world as well. ${ }^{7-12}$

It has been estimated that work-related UEMSDs and low back pain costs are between $0.5 \%$ and $2 \%$ of the EU's gross national product. ${ }^{1}$ UEMSDs are significant causes of disability claims cost, and lost productivity in many economic sectors worldwide. ${ }^{7}{ }^{13-16}$ In summary, UEMSDs are prevalent and costly demanding focused prevention campaigns.

The peer-reviewed literature about workplace prevention describes a variety of interventions that have been implemented and evaluated. ${ }^{17-25}$ However, few studies show sustainable positive effects on symptom, claim and disability outcomes. Overall, the studies and reviews to date reveal that there is no 'magic bullet' to deal with the significant burden of UEMSD. ${ }^{18-23}$ Consequently, systematic reviews, to date, have not been able to provide strong guidance for practice.

Despite the lack of guidance from literature, Occupational Health and Safety (OHS) practitioners have created workplace-based interventions to reduce UEMSD burden based on their training, knowledge and experiences. The challenges of conducting well-designed, rigorous evaluations have been a barrier to building the strong scientific evidence base necessary to guide practice. ${ }^{26-29}$ Poorly implemented interventions that could not be expected to lead to sustainable change in outcomes studied are another barrier. Kristensen ${ }^{26}$ has referred to this as programme failure versus theory failure. The implementation aspects of workplacebased interventions have been explored ${ }^{30-33}$ revealing the importance of intervention intensity, implementation, as well as scientific rigour.

A previous review Kennedy et $a l^{23}$ found moderate evidence for arm supports and limited evidence for ergonomics training plus workstation adjustments, new chair and rest breaks. Levels of evidence for interventions associated with 'no effect' were: there was also strong evidence for no effect of workstation adjustment alone; moderate evidence of no effect for biofeedback training and job stress management training; and limited evidence of no effect for cognitive behavioural training. The overall conclusion of the review was that it was not possible to make recommendations to practitioners about how to prevent or manage UEMSDs.

Therefore, the study objective was to systematically review the literature to synthesise the evidence on the effectiveness of workplace-based interventions focused on UEMSDs. This is the first update of the earlier review. ${ }^{23}$ Stakeholders from Ontario, Canada, were engaged iteratively throughout, particularly in refining evidence synthesis categories and developing practical messages based on the synthesis to support evidence-based practice. 


\section{METHODS}

The systematic review followed the six review steps developed by the Institute for Work \& Health (IWH) for OHS prevention reviews: ${ }^{34}$ (1) question development, (2) literature search, (3) relevance/inclusion screen, (4) quality appraisal, (5) data extraction and (6) synthesis. The review team participated in all review steps. Eleven researchers from Canada, Europe and the USA with expertise/experience in conducting MSD studies or systematic reviews comprised the team.

The IWH Systematic Review programme follows an integrated stakeholder engagement model during reviews. ${ }^{35}$ This results in stakeholders providing feedback throughout the review process. For this review, the stakeholders were all from Ontario and included ergonomists, policymakers, labour, employers, business and disability management consultants.

\section{Question development}

The review team and stakeholders participated in a meeting to discuss the review update research question, and proposed search terms. The review team and stakeholders retained the original review question and search terms for this update.

\section{Literature search}

Six electronic databases were searched: MEDLINE, EMBASE, Cumulative Index to Nursing \& Allied Health Literature (CINAHL), Canadian Centre for OHS's CCINFO web, Cochrane Library, and Ergonomic Abstracts from 2008 to April 2013. The databases were chosen based on those that yielded references in the original review and were still available. Additional databases were added to the search based on feedback from stakeholders. The search strategy was guided by the original review search and designed to be inclusive, using terms from three broad areas: work setting terms, intervention terms and health/claim outcome terms. The terms within the work setting and intervention categories were combined using a Boolean OR operator and the three main categories were then combined using a Boolean AND operator.

The search terms and database languages differ significantly; therefore, the search terms were customised. For the most part, the titles, abstracts or subject headings were searched for keywords.

In addition to the database searches, the reference lists of all papers selected for review were manually searched. The team also contacted experts in the field and sought out references that were prepublication to ensure a comprehensive search.

References were loaded into commercially available review software (DistillerSR), ${ }^{36}$ which was also used for all remaining review steps. DistillerSR is an online application designed specifically for the screening, quality appraisal and data extraction phases of a systematic review.

\section{Relevance screen}

The review team devised five screening criteria to exclude articles not relevant to our review question: (1) non-English or commentary/editorial; (2) study was not in a work setting; (3) no OHS intervention was evaluated; (4) no comparison group was used; and (5) study outcomes did not include upper extremity musculoskeletal symptoms, signs, disorders, injuries, claims or lost time. The review team decided to exclude non-English references based on low yields in the previous review and other preventions reviews. We note that the non-English articles were excluded due to other criteria in this review.
First, titles and abstracts of references were screened by a single reviewer. To limit the possibility of bias, a quality control (QC) step was implemented. A QC reviewer independently assessed a randomly chosen set of 446 titles and abstracts (approximately 5\% of references from the search). Comparing the QC reviewer responses directly to review team responses, 92 conflicts $(20 \%)$ were found. However, only $6(1.3 \%)$ were conflicts where the review team excluded references and the QC reviewer included them. Consequently, the review team is confident that the titles and abstracts were screened reflecting inclusion and exclusion requirements. The small (1.3\%) number of discrepancies suggests that reviewers had a similar understanding and application of the screening criteria.

Second, the remaining full-text articles were screened using the same criteria, with two reviewers independently reviewing and coming to consensus. When consensus could not be reached, a third reviewer was consulted. Third, relevance criteria were revisited in each subsequent review step and articles were excluded if the two reviewers were in consensus.

\section{Quality appraisal}

Relevant articles were appraised for methodological quality. Since this is a review update, ${ }^{23}$ the same criteria and scoring algorithm were used. Quality was assessed using 16 methodological criteria within the following broad headings: Design and Objectives, Level of Recruitment, Intervention Characteristics, Intervention Intensity, Outcomes, and Analysis.

Methodological quality scores for each article were based on a weighted sum score of 16 quality criteria (with a maximum score of 41). The weighting values assigned to the 16 criteria ranged from 'somewhat important' (1) to 'very important' (3). Each article received a quality ranking score by dividing the weighted score by 41 and then multiplying by 100 . The quality ranking was used to group articles into three categories: high $(>85 \%)$, medium $(50-85 \%)$ and low $(<50 \%)$ quality. ${ }^{23}$

Each article was independently assessed by two reviewers, who were required to reach consensus on all criteria. Where consensus could not be achieved, a third reviewer was consulted. Team members did not review articles they had consulted on, authored or co-authored.

The quality appraisal represents an assessment on: internal validity, external validity and statistical validity. ${ }^{37} \mathrm{~A}$ higher quality score increases the team's confidence that an effect was an intervention consequence versus the effect(s) of other workplace or external environment factors. Therefore, data extraction and evidence synthesis were only completed on high-quality and medium-quality studies.

\section{Data extraction}

Standardised forms based on the previous review were used. Extracted data were used to create summary tables sorted by intervention category and used for evidence synthesis. Data were extracted independently by pairs of reviewers. Again, reviewer pairs were rotated to reduce bias. Team members did not review articles they consulted on, authored or co-authored. Any conflicts between reviewers were resolved by discussion. Stakeholders were consulted to determine relevant intervention categories.

\section{Evidence synthesis}

The evidence synthesis approach ${ }^{34} 38$ considers the quality, quantity and consistency in the body of evidence (see table 1).

First, the intervention categories created in the data summary tables were examined by the entire team. Once consensus was 
Table 1 Best evidence synthesis algorithm/algorithm for messages

\begin{tabular}{|c|c|c|c|}
\hline Level of evidence & Minimum quality* and quantity & Consistency & Strength of message \\
\hline Strong & 3 High $(H)$ & $3 \mathrm{H}$ agree; if $3+$ studies, $3 / 4$ of the $\mathrm{M}$ and $\mathrm{H}$ agree & Recommendations \\
\hline Moderate & $2 \mathrm{H}$ or $2 \mathrm{H}$ and 1 Medium (M) & $\begin{array}{l}2 \mathrm{H} \text { agree or } 2 \mathrm{M} \text { and } 1 \mathrm{H} \text { agree; } \\
\text { if } 3+,>2 / 3 \text { of the } \mathrm{M} \text { and } \mathrm{H} \text { agree }\end{array}$ & Practice considerations \\
\hline Limited & $1 \mathrm{H}$ or $2 \mathrm{M}$ or $1 \mathrm{M}$ and $1 \mathrm{H}$ & $\begin{array}{l}2(\mathrm{M} \text { and/or } \mathrm{H}) \text { agree; } \\
\text { if } 2+,>1 / 2 \text { of the } \mathrm{M} \text { and } \mathrm{H} \text { agree }\end{array}$ & $\begin{array}{l}\text { Not enough evidence to make recommendations } \\
\text { or practice considerations }\end{array}$ \\
\hline Mixed & 2 & Findings are contradictory & \\
\hline Insufficient & \multicolumn{3}{|c|}{ Medium-quality studies that do not meet the above criteria } \\
\hline
\end{tabular}

reached on the categories, the team moved to summarising the evidence per category. Owing to the heterogeneity across outcome measures, study designs and reported data, we chose not to calculate a pooled effect estimate. To determine individual study intervention effects, the following rules were applied: an intervention with a positive and no negative results was classified as positive effect, an intervention with both positive and no effect was also classified as positive effect, an intervention with only no effects was classified as no effect, an intervention with any negative effect was classified as negative effect. The direction of the intervention effect was considered along with study quality rating and number of studies to determine the level of evidence for each intervention category (see table 1).

To reach a strong level of evidence, there had to be at least three high-quality studies that had that same direction of effect or at least $75 \%$ of all studies within the intervention category had to have the same direction of effect.

To generate practical messages, an algorithm developed by IWH along with OHS stakeholders was followed. ${ }^{39}$ A strong level of evidence leads to 'recommendations'. A moderate level of evidence leads to 'practice considerations'. For all evidence levels below moderate, the consistent message is: 'Not enough evidence from the scientific literature to guide current policies/ practices'. This does not mean that the interventions with limited, mixed or insufficient evidence may not be effective; only that there is not enough scientific evidence to draw conclusions.

\section{RESULTS}

\section{Literature search}

The search (covering 2008-April 2013) identified 9908 references once results from EMBASE, MEDLINE, Ergonomic Abstracts, CINAHL, Cochrane Library, CCInfoWeb were combined and duplicates removed. One additional paper was identified by the research team that was not captured by the search, resulting in a total of 9909 references (figure 1).

\section{Relevance screen}

Overall, 9655 references and 216 full articles were excluded for not meeting relevance criteria (reference list is available from corresponding author on request). The remaining 38 relevant articles described 30 unique studies (figure 1).

\section{Quality appraisal}

Four studies were classified as low quality $(<50 \%$ of criteria met), 14 studies were medium quality (50-85\% of criteria met), and 12 studies were high quality ( $>85 \%$ of criteria met; see online supplementary table S2). Low-quality studies had high loss to follow-up, found differences in baseline characteristics between intervention and control groups, participants' outcomes were not analysed by the groups they were originally allocated to, and the statistical analyses were not optimised for best results (eg, not accounting for baseline differences). The quality criteria that differentiated medium-quality and highquality studies were also loss to follow-up and whether statistical methods were optimised for best results.

Four low-quality studies ${ }^{40-43}$ did not move on to data extraction leaving 26 studies (34 articles) for data extraction.

\section{Data extraction}

Study characteristics

The study designs included randomised controlled trials $(n=9)$, cluster-randomised controlled trials $(\mathrm{n}=12)$ and nonrandomised trials with a control group $(\mathrm{n}=5)$.

The studies came from the Netherlands $(\mathrm{n}=7)$, Denmark $(n=6)$, Finland $(n=3)$, Italy $(n=2)$, the USA $(n=2)$, India $(n=1)$, Canada $(n=1)$, Brazil $(n=1)$, Malaysia $(n=1)$, Sweden $(n=1)$ and Israel $(\mathrm{n}=1)$.

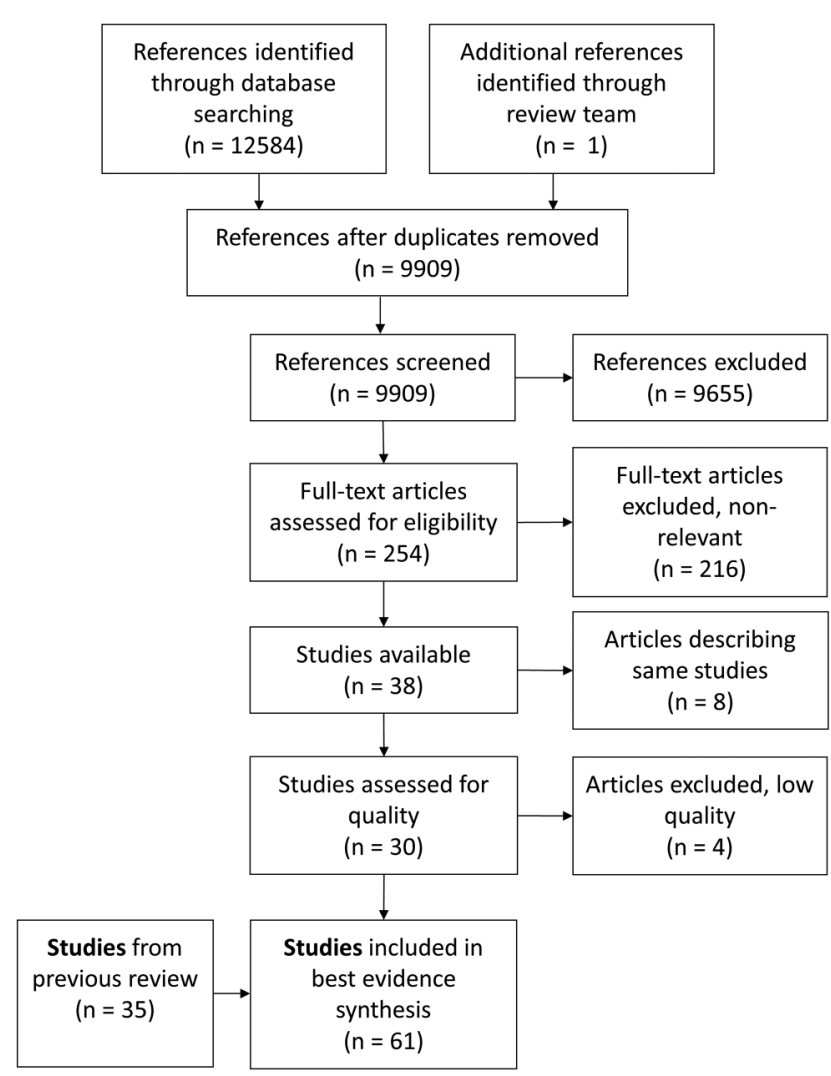

Figure 1 Flow chart of study identification, selection and synthesis. 
The sectors included public administration $(n=5)$, professional, scientific or technical services $(n=5)$, manufacturing $(n=3)$, retail $(n=1)$, healthcare and social assistance $(n=5)$, educational services $(n=4)$, hospitality $(n=1)$, armed services $(n=1)$, municipality $(n=1)$, other $(n=9)$, and unknown $(n=1)$. Some studies included populations from multiple sectors. Out of the 26 studies, 16 were considered office based. Overall, positive effects were reported for at least one outcome in 19 of the 26 studies.

\section{Combining studies from original and update}

To present an up-to-date synthesis of the evidence, we combined 35 studies $^{46}{ }^{79-112}$ from the original review $^{23}$ with the 26 studies from the update for a total of 61 studies.

\section{Intervention effects}

There were no negative effects reported in the 61 studies (see online supplementary table S3). The most common UEMSD outcome reported was symptoms. Additional outcomes included sickness absence, disability, disorders (diagnosed) and physical function.

\section{Evidence synthesis}

The interventions across the 61 studies were grouped into 30 different intervention categories (see online supplementary table S3) and evidence synthesis for each category was determined (table 2). The intervention category evidence was paired with practical messages (table 2 ).

The message content was determined through iterative stakeholder consultations to improve practicality. The messages were worded to help clarify the strength of the evidence, limit misinterpretation and increase user uptake.

Seven studies were identified and grouped within the resistance exercise category. Four high-quality ${ }^{44-47}$ and three medium-quality studies ${ }^{48-50}$ presented a positive effect of resistance exercise, such as dumbbell or kettlebell exercises, on UEMSD outcomes (see online supplementary table S3 for a more complete description of the resistance training programmes; see table 3 for a description of the work environments and sector). The strong level of evidence resulted in the message: implementing a workplace-based resistance training exercise programme can help prevent and manage UEMSD and symptoms.

Three intervention categories had a moderate level of evidence showing a positive effect on UEMSD outcomes (see tables 2, 3 and see online supplementary table S3 for details). The forearm supports category had evidence from two highquality studies ${ }^{79} 91$ and one medium-quality study. ${ }^{80}$ The vibration feedback about static mouse use category includes evidence from two high quality studies ${ }^{62} 67$ and one medium quality study. ${ }^{53}$ The stretching exercise programmes category includes evidence from one high-quality study ${ }^{68-70}$ and five medium-

Table 2 Level of evidence for UEMSD interventions and accompanying messages

\begin{tabular}{|c|c|c|}
\hline $\begin{array}{l}\text { Level of evidence } \\
\text { (direction of effect)* }\end{array}$ & Intervention (number of studies) $\dagger$ & Message \\
\hline Strong (positive) & - Resistance training (7) & $\begin{array}{l}\text { Implementing a workplace-based resistance training exercise programme, } \\
\text { policy or practice can help manage and prevent UEMSD symptoms and } \\
\text { disabilities }\end{array}$ \\
\hline Moderate (positive) & $\begin{array}{l}\text { Stretching exercise programmes (includes UE component) (6) } \\
\text { Vibration feedback on static mouse use (3) } \\
\text { Forearm supports (workstation) (3) }\end{array}$ & Consider implementing in practices if applicable to the work context \\
\hline Moderate (no effect) & $\begin{array}{l}\text { Job stress management training (UE outcomes) (2) } \\
\text { Biofeedback (EMG) training (5) } \\
\text { - Workstation adjustment alone (minimal worker engagement) (5) }\end{array}$ & Seek alternative interventions based on OHS experience/knowledge \\
\hline Limited (positive) & $\begin{array}{l}\text { Aerobic exercise programmes (3) } \\
\text { Alternative keyboard (force profile) (1) } \\
\text { - Trackball pointing device (+l- arm supports) (1) } \\
\text { - Rest breaks (5) } \\
\text { Postural exercise programme (1) } \\
\text { - Specialised exercise program (Feldenkrais) (1) } \\
\text { - Curved seat pan chair (non-office) (1) } \\
\text { - Lighter/wider dental tools (1) } \\
\text { - Neuromuscular exercise (non-office) (1) }\end{array}$ & $\begin{array}{l}\text { Not enough evidence from the scientific literature to guide current } \\
\text { policies/practices }\end{array}$ \\
\hline Limited (no effect) & $\begin{array}{l}\text { Work redesign to minimise shoulder load (non-office) (4) } \\
\text { Joystick pointing device (+/- arm supports) (1) } \\
\text { Neck school programme (1) individualised exercise programme } \\
\text { (+l- stress management) (1) }\end{array}$ & $\begin{array}{l}\text { Not enough evidence from the scientific literature to guide current } \\
\text { policies/practices }\end{array}$ \\
\hline Mixed & $\begin{array}{l}\text { Ergonomics training+workstation adjustment (8) } \\
\text { Low-intensity participatory ergonomics (PE) programmes (4) } \\
\text { Cognitive behavioural training programme (2) } \\
\text { - Ergonomics training (2) }\end{array}$ & $\begin{array}{l}\text { Not enough evidence from the scientific literature to guide current } \\
\text { policies/practices }\end{array}$ \\
\hline Insufficient & $\begin{array}{l}\text { Rest breaks plus exercise (1) } \\
\text { Reduced hours (1) } \\
\text { - Alternative keyboard (split) (1) } \\
\text { Individual interventions (office) (1) } \\
\text { Patient handling programme (1) } \\
\text { OHS training (2-3 h) and/or ergonomic advice/change and/pr } \\
\text { exercise and/or medical examination (1) }\end{array}$ & $\begin{array}{l}\text { Not enough evidence from the scientific literature to guide current } \\
\text { policies/practices }\end{array}$ \\
\hline
\end{tabular}


Table 3 Characteristics of studies

\begin{tabular}{|c|c|c|c|c|}
\hline Author, year & Country & Study design & Industry/sector job titles & Sample size \\
\hline Andersen, $2012^{45}$ & Denmark & Cluster-RCT & Public administration & $\begin{array}{l}I 1=116, I 2=126,13=106 \\
C 1=101\end{array}$ \\
\hline $\begin{array}{l}\text { Andersen, 2008, } 2010^{514} \text {; } \\
\text { Blangsted, 2008 }\end{array}$ & Denmark & Cluster-RCT & Public administration & $11=180,12=187$ \\
\hline De Kraker, $2008^{53}$ & The Netherlands & $\mathrm{RCT}$ & Other: call centre & $11=46$ \\
\hline Driessen, 2011, 2008, 2011, 2012 $54-57$ & The Netherlands & Cluster-RCT & $\begin{array}{l}\text { Professional, scientific or technical services; } \\
\text { healthcare and social assistance; manufacturing; } \\
\text { other: rail and airline companies }\end{array}$ & I1=1472 (19 departments) \\
\hline Haukka, $2008^{58}$ & Finland & Cluster-RCT & Retail; hospitality & 59 kitchens, 263 workers \\
\hline Heinrich, $2009^{59}$ & The Netherlands & $\mathrm{RCT}$ & $\begin{array}{l}\text { Other: predominantly agricultural workers but } \\
\text { also other occupations }\end{array}$ & $11=53 ; 12=76$ \\
\hline Jay, $2011^{44}$ & Denmark & $\mathrm{RCT}$ & Professional, scientific or technical services & $11=20$ \\
\hline Jepsen, $2008^{60}$ & Denmark & $\begin{array}{l}\text { Non-randomised field } \\
\text { trial }\end{array}$ & Professional, scientific or technical services & 125 \\
\hline Joshi, $2011^{61}$ & India & $\mathrm{RCT}$ & Educational services & $11=30$ \\
\hline King, $2013^{62}$ & Canada & $\mathrm{RCT}$ & Professional, scientific or technical services & $\mathrm{I}=11$ \\
\hline Lacaze, $2010^{63}$ & Brazil & $\begin{array}{l}\text { Non-randomised field } \\
\text { trial }\end{array}$ & $\begin{array}{l}\text { Other: transportation and warehousing- } \\
\text { flight-booking operators from the call centre of } \\
\text { one airline }\end{array}$ & 32 \\
\hline Levanon, 2012, $2012^{6465}$ & Not specified & Before and after design & Other: hi tech firms & $11=23,12=22$ \\
\hline Mahmud, $2011^{66}$ & Malaysia & Cluster-RCT & Educational services & $11=69$ \\
\hline Meijer, $2009^{67}$ & The Netherlands & Cluster-RCT & Other: governmental institute & $\mathrm{I}=178$ \\
\hline Mongini, 2008, 2009, 2010 $68-70$ & Italy & $\begin{array}{l}\text { Non-randomised field } \\
\text { trial }\end{array}$ & Municipality & $\mathrm{I}=192$ \\
\hline Parkkari, $2011^{71}$ & Finland & Cluster-RCT & Armed services & $\mathrm{I}=536$ \\
\hline Pedersen, $2009^{50}$ & Denmark & Cluster-RCT & Public administration & $|1=180 ;| 2=187$ \\
\hline Pillastrini, $2009^{48}$ & Italy & Cluster-RCT & Educational services & $11=35$ \\
\hline Rempel, $2012^{72}$ & USA & Cluster-RCT & Healthcare and social assistance & $11=56$ \\
\hline Robertson, $2008^{73}$ & USA & $\begin{array}{l}\text { Non-randomised field } \\
\text { trial }\end{array}$ & Professional, scientific or technical services & $\mathrm{I} 1=61, \mathrm{I} 2 \mathrm{~N}=$ not provided \\
\hline Shiri, $2011^{74}$ & Finland & $\mathrm{RCT}$ & $\begin{array}{l}\text { Public Administration; Manufacturing; Healthcare } \\
\text { \& social assistance; Other: 'Warehouse workers'? }\end{array}$ & $\mathrm{I}=91$ \\
\hline Spekle, $2010^{75}$ & The Netherlands & $\mathrm{RCT}$ & $\begin{array}{l}\text { Healthcare and social assistance; educational } \\
\text { services; municipality; other: nature conservation, } \\
\text { regulatory affairs }\end{array}$ & $11=605$ \\
\hline van Eijsden-Besseling, $2008^{76}$ & The Netherlands & $\mathrm{RCT}$ & Unknown & $11=44,12=44$ \\
\hline Vermeulen, $2011^{77}$ & The Netherlands & $\mathrm{RCT}$ & Public administration; other services & 79 \\
\hline Von Thiele Schwarz, $2008^{78}$ & Sweden & Cluster-RCT & Healthcare and social assistance & 162 \\
\hline Zebis, $2011^{49}$ & Denmark & Cluster-RCT & Manufacturing & $\mathrm{I}=282$ \\
\hline
\end{tabular}

C, control; I, intervention; RCT, randomised controlled trial.

quality studies. 6061638182 The moderate level of evidence of a positive effect resulted in the message: consider implementing these interventions if applicable to the work context.

Three additional studies showed a moderate level of evidence for no effect on UEMSD outcomes. These intervention categories include: EMG biofeedback with two high-quality studies ${ }^{83} 84$ and three medium-quality studies; ${ }^{64} 658586$ job stress management training category with two high-quality studies; ${ }^{87} 88$ and office workstation adjustment category with one high-quality study $^{89}$ and three medium-quality studies. ${ }^{73} 7490$ Since there was a moderate level of evidence that these three intervention categories have no effect on UEMSD outcomes, the resulting message is: seek alternatives if possible based on your OHS experience/knowledge.

The remaining 23 intervention categories had too few highquality studies or had conflicting evidence across studies, resulting in the message: there is not enough evidence from the scientific literature to guide current policies or practices. For a message to be provided for these interventions, more highquality evidence is needed (table 2).

\section{DISCUSSION}

Preventing UEMSD injury and disability is challenging. OHS practitioners are charged with designing and implementing solutions. Evidence-based approaches should help identify and implement more effective solutions. Optimal evidence-based practice employs the knowledge and experience of practitioners along with the most up-to-date evidence from the scientific literature in the context of the client (patient, worker, etc) to determine prevention solutions. ${ }^{113}$

It can be challenging for busy OHS practitioners to find and read the latest research on any given topic. This challenge is compounded by the increase in the number of OHS publications year to year. Using the same literature search strategy as the earlier review, ${ }^{23}$ we found over 9900 references in a 5-year period (2008-2013) as compared with approximately 15400 in a much longer period (mid-1960s-2008). We did find a higher proportion of relevant high-quality studies $(50 \%$ vs $39 \%)$ in the past 5 years as compared with the original review. ${ }^{23}$

The current review and evidence update gathers and synthesises the scientific literature and presents practical messages for 
OHS practitioners. The review team consulted with OHS stakeholders to help ensure the messages were useful and applicable in practice.

Combining newer studies with those from the original review resulted in the potential for stronger levels of evidence according to our synthesis approach. However, the new studies also resulted in a greater number of intervention categories as compared with the original review. While we found a strong level of evidence for the positive effect of resistance training, the remaining findings were quite consistent with the original review. Our finding of moderate levels of evidence for positive effects of arm supports is consistent with the original review as is the moderate evidence for no effect of EMG biofeedback and of job stress management training. Kennedy et $a l^{23}$ found a strong level of evidence for no effect of workstation adjustments alone, while in the current update, a moderate level of evidence was found. In this case, one of the newer medium-quality studies had a positive outcome; we note that worker engagement was higher in the recent studies than it was in the original studies, which also contributed to the change in level of evidence.

The diversity of workplace-based interventions for UEMSD likely reflects the variety of potential relevant hazards, the number and types of UEMSD, the distinctness of workplaces, and the practical challenges of trying to design, implement and evaluate policies, programmes and practices. We note that there are many studies (approximately 60\%) conducted in office-based workplaces. There are a number of potential reasons for this: the prevalence of UEMSD in office-workers, ${ }^{1}$ the nature of the work and workplace with similar equipment designs and work patterns, or possibly because it is easier to conduct an evaluation in an office setting. Office settings may have more consistent work schedules (less shift work), typically there are individual (non-shared) workstations, and the workstation can be relatively easily modified (through adjustment or alternative products). While it may be more challenging to implement and study interventions in non-office settings, our findings suggest it is possible.

Our findings are consistent with other recent reviews that included workplace-based interventions. ${ }^{17} 18 \quad 114115$ Reviews that focused on RCTs only and attempted a meta-analysis also did not find strong levels of evidence for workplace interventions. ${ }^{19-22}$ While the findings are consistent, our synthesis of workplace-based interventions to prevent and manage UEMSD includes practical messages for, and developed with, practitioners.

A unique aspect of this review (update) was the integration of messages related to the levels of evidence developed with OHS stakeholders. ${ }^{39}$ We shared our review findings with multiple groups of OHS stakeholders and received feedback about how to create useful messages. The iterative approach $^{35}$ led to concise messages that focused on practice as well as context that a varied group of OHS stakeholders agreed on. The messages are in keeping with an evidencebased practice approach. They provide recommendations or practice considerations to be weighed by the practitioner based on their own knowledge and experience along with the context and end-user needs.

Despite the useful messages provided here, more high-quality workplace-based intervention research is required. Current studies show high-quality evaluations that incorporate concurrent comparison groups (in some cases using randomisation) can be designed and performed. Importantly, the interventions must be properly implemented.

\section{Strengths and limitations}

A meta-analysis was not conducted due to the substantial intervention heterogeneity, different workplace contexts and study designs. Instead, a best evidence synthesis (BES) approach consistent with the original review ${ }^{23}$ was used. While this approach has been criticised, ${ }^{27}$ it provides practitioners with useful information. In addition, the BES is a transparent approach with clearly defined criteria to determine the level of evidence. Beyond the messages that arise from the consistent algorithm employed, practitioners can also consider the evidence from the individual studies. This is especially useful when there are few studies available for a given intervention type. Practitioners must come up with solutions even when there is a lack of scientific evidence available.

The likelihood of publication bias was not addressed; however, we included many relevant peer-reviewed studies that reported no effects for important outcomes. A key aspect of publication bias is that studies reporting positive effects are more likely to be published. While publication bias cannot be ruled out, the number of studies reporting no effects suggests publication bias is not a significant issue in this synthesis.

To determine intervention effects from individual studies, we decided to classify an intervention effect as positive when the study reported any positive result. This followed the method used in the original review. ${ }^{23}$ Hence, if a single study outcome regarding UEMSD showed positive results while several other UEMSD study outcomes showed no effect, then this study was still classified as positive intervention effect. Since classification of effect is often based on the primary outcome results, it should be noted that we were not conservative in this part of our evidence synthesis approach. However, we feel that any positive effect might benefit workers and should be taken into account in evidence-based practice.

A particular strength of the synthesis is the OHS stakeholder engagement throughout the review process. Stakeholders helped ensure we were asking a relevant question. Stakeholders were also asked for advice regarding possible literature search terms to ensure our search was up-to-date. Stakeholders were consulted about our findings and how to word the messages for OHS practitioners (consultants or in the workplace) to support evidence-based practice approaches.

\section{CONCLUSIONS}

Our synthesis update of the scientific literature identified 30 different intervention types from 61 evaluation studies. There were many intervention types that did not meet the criteria for high or moderate levels of evidence. However, we note that this does not mean that the interventions are not effective, only that there is insufficient evidence to support recommending these interventions based on the scientific evidence.

No intervention evaluations produced negative effects (eg, increased symptoms or lost time claims). However, job stress management training, EMG biofeedback training and workstation adjustment alone interventions had a moderate level of evidence of no effect for UEMSD outcomes. Practitioners should consider seeking alternative interventions based on OHS experience/knowledge.

Stretching exercise programmes, vibration feedback on mouse use and workstation forearm supports had a moderate level of evidence for a positive effect in preventing UEMSD. Practitioners should consider implementing stretching exercise programmes, vibration feedback on mouse use or workstation forearm supports in practices if applicable to the work context. 
Resistance training programmes had a strong level of evidence. We recommend implementing a workplace-based resistance training exercise programme to help prevent and manage UEMSD symptoms and disorders.

\section{Author affiliations}

${ }^{1}$ Institute for Work \& Health, Toronto, Ontario, Canada

${ }^{2} S$ chool of Public Health and Health Systems, University of Waterloo, Waterloo, Ontario, Canada

${ }^{3}$ Division of Occupational and Environmental Medicine, School of Medicine, University of California, San Francisco, Richmond, California, USA

${ }^{4}$ CB\&l, Inc, The Woodlands, Texas, USA

${ }^{5}$ Department of Public and Occupational Health, EMGO Institute for Health and Care Research, VU University Medical Center, Amsterdam, The Netherlands

${ }^{6}$ Department of Physical Therapy, Movement \& Rehabilitation Science, Northeastern University, Boston, Massachusetts, USA

${ }^{7}$ School of Public Health, Institute for Health Policy, University of Texas Health Science Center at Houston, Houston, Texas, USA

${ }^{8} \mathrm{MRC} / \mathrm{CSO}$ Social and Public Health Sciences Unit, University of Glasgow, Glasgow, UK

${ }^{9}$ Florida International University, Robert Stempel College of Public Health and Social Work, Miami, Florida, USA

Acknowledgements Quenby Mahood, Joanna Liu and the IWH library for valuable help with search strategy design/execution and article acquisition. Trevor King for knowledge transfer and exchange activities and stakeholder engagement. Our stakeholders for their suggestions about practical messages. The Institute for Work \& Health operates with the support of the Province of Ontario. The views expressed in this publication are those of the authors and do not necessarily reflect those of the Province of Ontario.

Contributors DVE and El conceived the study with input from BA. El developed the search strategy with library support (acknowledged), all authors reviewed the search terms. All authors contributed to article screening, quality appraisal, data extraction and synthesis. DVE, CM and El wrote the draft paper. All authors contributed to writing, reviewing or revising the paper and have read and approved the final manuscript.

Funding Ontario Ministry of Labour. KS is funded by the UK Medical Research Council (MCUU12017/8 and MCPC13027).

Competing interests None declared.

Provenance and peer review Not commissioned; externally peer reviewed.

Open Access This is an Open Access article distributed in accordance with the Creative Commons Attribution Non Commercial (CC BY-NC 4.0) license, which permits others to distribute, remix, adapt, build upon this work non-commercially, and license their derivative works on different terms, provided the original work is properly cited and the use is non-commercial. See: http://creativecommons.org/ licenses/by-nc/4.0/

\section{REFERENCES}

1 Schneider E, Irastorza X. OSH in figures: work-related musculoskeletal disorders in the EU-facts and figures. Luxembourg: European Agency for Safety and Health at Work (EU-OSHA), 2010.

2 Silverstein B, Evanoff B. Musculoskeletal disorders. In: Levy BS, Wegman DH, Baron SL, et al., eds. Occupational and environmental health: recognizing and preventing disease and injury. New York, NY: Oxford University Press, 2011:335-65.

3 Workers Compensation Board of Manitoba. Annual report 2009. Winnipeg, MB: Workers Compensation Board of Manitoba, 2010.

4 Workplace Safety and Insurance Board (WSIB). Statistical supplement to the 2009 annual report (2009). Toronto, ON: Workplace Safety and Insurance Board (WSIB), 2010.

5 WorkSafeBC. WorkSafeBC statistics 2009. Vancouver, BC: WorkSafeBC, 2010.

6 Workers' Compensation Board of Nova Scotia. Annual report 2009. Halifax, NS: Workers' Compensation Board of Nova Scotia, 2010.

7 Vos T, Flaxman AD, Naghavi M, et al. Years lived with disability (YLDs) for 1160 sequelae of 289 diseases and injuries 1990-2010: a systematic analysis for the Global Burden of Disease Study 2010. Lancet 2012;380: 2163-96.

8 Piedrahita H. Costs of work-related musculoskeletal disorders (MSDs) in developing countries: Colombia case. Int J Occup Saf Ergon 2006;12:379-86.

9 Meo SA, Alsaaran ZF, Alshehri MK, et al. Work-related musculoskeletal symptoms among building construction workers in Riyadh, Saudi Arabia. Pak J Med Sci 2013:29:1394-9.

10 Alghadir A, Anwer S. Prevalence of musculoskeletal pain in construction workers in Saudi Arabia. Sci World J 2015;2015:529873.
11 Loghmani A, Golshiri P, Zamani A, et al. Musculoskeletal symptoms and job satisfaction among office-workers: a cross-sectional study from Iran. Acta Med Acad 2013:42:46-54.

12 Inbaraj LR, Haebar OJ, Saj F, et al. Prevalence of musculoskeletal disorders among brick kiln workers in rural Southern India. Indian I Occup Environ Med 2013;17:71-5.

13 Murray CJ, Vos T, Lozano R, et al. Disability-adjusted life years (DALYs) for 291 diseases and injuries in 21 regions, 1990-2010: a systematic analysis for the Global Burden of Disease Study 2010. Lancet 2012;380:2197-223.

14 Tornqvist EW, Hagberg M, Hagman M, et al. The influence of working conditions and individual factors on the incidence of neck and upper limb symptoms among professional computer users. Int Arch Occup Environ Health 2009:82:689-702.

15 Walker-Bone K, Palmer KT, Reading I, et al. Prevalence and impact of musculoskeletal disorders of the upper limb in the general population. Arthritis Rheum 2004;51:642-51.

16 Woolf $A D$, Erwin J, March L. The need to address the burden of musculoskeletal conditions. Best Pract Res Clin Rheumatol 2012;26:183-224.

17 Varatharajan S, Cote P, Shearer HM, et al. Are work disability prevention interventions effective for the management of neck pain or upper extremity disorders? A systematic review by the Ontario Protocol for Traffic Injury Management (OPTIMa) collaboration. J Occup Rehabil 2014;24:692-708

18 Nastasia I, Coutu MF, Tcaciuc R. Topics and trends in research on non-clinical interventions aimed at preventing prolonged work disability in workers compensated for work-related musculoskeletal disorders (WRMSDs): a systematic, comprehensive literature review. Disabil Rehabil 2014;36:1841-56.

19 Hoe VC, Urquhart DM, Kelsall HL, et al. Ergonomic design and training for preventing work-related musculoskeletal disorders of the upper limb and neck in adults. Cochrane Database Syst Rev 2012;8:CD008570.

20 Montano D, Hoven H, Siegrist J. A meta-analysis of health effects of randomized controlled worksite interventions: does social stratification matter? Scand I Work Environ Health 2014;40:230-4.

21 Montano D, Hoven $\mathrm{H}$, Siegrist J. Effects of organisational-level interventions at work on employees' health: a systematic review. BMC Public Health 2014;14:135.

22 Verhagen AP, Bierma-Zeinstra Sita MA, Burdorf $A$, et al. Conservative interventions for treating work-related complaints of the arm, neck or shoulder in adults. Cochrane Database Syst Rev 2013;12:CD008742.

23 Kennedy CA, Amick BC III, Dennerlein JT, et al. Systematic review of the role of occupational health and safety interventions in the prevention of upper extremity musculoskeletal symptoms, signs, disorders, injuries, claims and lost time. J Occup Rehabil 2010:20:127-62.

24 Tullar JM, Brewer S, Amick BC III, et al. Occupational safety and health interventions to reduce musculoskeletal symptoms in the health care sector. J Occup Rehabil 2010:20:199-219.

25 Brewer S, Van Eerd D, Amick BC III, et al. Workplace interventions to prevent musculoskeletal and visual symptoms and disorders among computer users: a systematic review. J Occup Rehabil 2006;16:325-58.

26 Kristensen TS. Intervention studies in occupational epidemiology. Occup Environ Med 2005;62:205-10.

27 Verbeek J, Husman K, van Dijk F, et al. Building an evidence base for occupational health interventions. Scand J Work Environ Health 2004;30:164-70.

28 Punnett L. Musculoskeletal disorders and occupational exposures: how should we judge the evidence concerning the causal association? Scand I Public Health 2014;42(13 Suppl):49-58.

29 Ruotsalainen JH, Verbeek JH, Salmi JA, et al. Evidence on the effectiveness of occupational health interventions. Am J Ind Med 2006;49:865-72.

30 Cole DC, Theberge N, Dixon SM, et al. Reflecting on a program of participatory ergonomics interventions: a multiple case study. Work 2009;34:161-78.

31 Wells R, Laing A, Cole D. Characterizing the intensity of changes made to reduce mechanical exposure. Work 2009;34:179-93.

32 Driessen MT, Proper $\mathrm{Kl}$, Anema JR, et al. Process evaluation of a participatory ergonomics programme to prevent low back pain and neck pain among workers. Implement Sci 2010;5:65.

33 Baril-Gingras $G$, Bellemare M, Brun JP. The contribution of qualitative analyses of occupational health and safety interventions: an example through a study of external advisory interventions. Saf Sci 2006;44:851-74.

34 Irvin E, Van Eerd D, Amick BC III, et al. Introduction to special section: systematic reviews for prevention and management of musculoskeletal disorders. J Occup Rehabil 2010;20:123-6.

35 Keown K, Van Eerd D, Irvin E. Stakeholder engagement opportunities in systematic reviews: knowledge transfer for policy and practice. I Contin Educ Health Prof 2008:28:67-72.

36 Evidence Partners. DistillerSR electronic online systematic review software. Ottawa, Canada: Evidence Partners, 2015.

37 Shadish WR, Cook TD, Campbell DT. Experimental and quasi-experimental designs for generalized causal inference. Boston: Houghton Mifflin, 2002.

38 Slavin RE. Best-evidence synthesis: an alternative to meta-analytic and traditional reviews. Educ Res 1986;15:5-11. 
39 Institute for Work \& Health. Evidence and quality... saying what works clearly! Toronto: Institute for Work \& Health, 2007.

40 Bernaards CM, Bosmans JE, Hildebrandt VH, et al. The cost-effectiveness of a lifestyle physical activity intervention in addition to a work style intervention on recovery from neck and upper limb symptoms and pain reduction in computer workers. Occup Environ Med 2011;68:265-72.

41 Laestadius JG, Ye J, Cai X, et al. The proactive approach-is it worthwhile? A prospective controlled ergonomic intervention study in office workers. J Occup Environ Med 2009;51:1116-24.

42 Choobineh A, Motamedzade M, Kazemi M, et al. The impact of ergonomics intervention on psychosocial factors and musculoskeletal symptoms among office workers. Int J Ind Ergon 2011;41:671-6.

43 Pereira CC, Lopez RF, Vilarta R. Effects of physical activity programmes in the workplace (PAPW) on the perception and intensity of musculoskeletal pain experienced by garment workers. Work 2013:44:415-21.

44 Jay K, Frisch D, Hansen K, et al. Kettlebell training for musculoskeletal and cardiovascular health: a randomized controlled trial. Scand I Work Environ Health 2011:37:196-203

45 Andersen $\mathrm{CH}$, Andersen LL, Gram B, et al. Influence of frequency and duration of strength training for effective management of neck and shoulder pain: a randomised controlled trial. Br J Sports Med 2012:46:1004-10.

46 Sjogren T, Nissinen KJ, Jarvenpaa SK, et al. Effects of a workplace physical exercise intervention on the intensity of headache and neck and shoulder symptoms and upper extremity muscular strength of office workers: a cluster randomized controlled cross-over trial. Pain 2005;116:119-28.

47 Andersen LL, Jorgensen MB, Blangsted AK, et al. A randomized controlled intervention trial to relieve and prevent neck/shoulder pain. Med Sci Sports Exerc 2008:40:983-90.

48 Pillastrini P, Mugnai R, Bertozzi L, et al. Effectiveness of an at-work exercise program in the prevention and management of neck and low back complaints in nursery school teachers. Ind Health 2009;47:349-54.

49 Zebis MK, Andersen LL, Pedersen MT, et al. Implementation of neck/shoulder exercises for pain relief among industrial workers: a randomized controlled trial. BMC Musculoskelet Disord 2011;12:205.

50 Pedersen MT, Blangsted AK, Andersen LL, et al. The effect of worksite physical activity intervention on physical capacity, health, and productivity: a 1-year randomized controlled trial. J Occup Environ Med 2009;51:759-70.

51 Andersen LL, Zebis MK, Pedersen MT, et al. Protocol for work place adjusted intelligent physical exercise reducing musculoskeletal pain in shoulder and neck (VIMS): a cluster randomized controlled trial. BMC Musculoskelet Disord 2010;11:173.

52 Blangsted AK, Sogaard K, Hansen EA, et al. One-year randomized controlled trial with different physical-activity programs to reduce musculoskeletal symptoms in the neck and shoulders among office workers. Scand I Work Environ Health 2008:34:55-65.

53 De Kraker H, De Korte EM, Van Mil FL, et al. The effect of a feedback signal in a computer mouse on hovering behaviour, productivity, comfort and usability in a field study. Ergonomics 2008:51:140-55.

54 Driessen $\mathrm{M}$, Bosmans J, Proper $\mathrm{K}$, et al. The economic evaluation of a participatory ergonomics programme to prevent low back and neck pain. Work 2012;41(Suppl 1):2315-20

55 Driessen MT, Proper KI, Anema JR, et al. Participatory ergonomics to reduce exposure to psychosocial and physical risk factors for low back pain and neck pain: results of a cluster randomised controlled trial. Occup Environ Med 2011;68:674-81.

56 Driessen MT, Anema JR, Proper Kl, et al. Stay@Work: participatory ergonomics to prevent low back and neck pain among workers: design of a randomised controlled trial to evaluate the (cost-) effectiveness. BMC Musculoskelet Disord 2008;9:145.

57 Driessen MT, Proper KI, Anema JR, et al. The effectiveness of participatory ergonomics to prevent low-back and neck pain-results of a cluster randomized controlled trial. Scand I Work Environ Health 2011;37:383-93.

58 Haukka E, Leino-Arjas P, Viikari-Juntura E, et al. A randomised controlled trial on whether a participatory ergonomics intervention could prevent musculoskeletal disorders. Occup Environ Med 2008;65:849-56.

59 Heinrich J, Anema JR, de Vroome EM, et al. Effectiveness of physical training for self-employed persons with musculoskeletal disorders: a randomized controlled trial. BMC Public Health 2009:9:200.

60 Jepsen JR, Thomsen G. Prevention of upper limb symptoms and signs of nerve afflictions in computer operators: the effect of intervention by stretching. J Occup Med Toxicol 2008;3:1.

61 Joshi VS, Bellad AS. Effect of yogic exercises on symptoms of musculoskeletal disorders of upper limbs among computer users: a randomised controlled trial. Indian J Med Sci 2011;65:424-8.

62 King TK, Severin CN, Van Eerd D, et al. A pilot randomised control trial of the effectiveness of a biofeedback mouse in reducing self-reported pain among office workers. Ergonomics 2013;56:59-68.

63 Lacaze DH, Sacco Ide C, Rocha LE, et al. Stretching and joint mobilization exercises reduce call-center operators' musculoskeletal discomfort and fatigue. Clinics (Sao Paulo) 2010;65:657-62
64 Levanon Y, Gefen A, Lerman Y, et al. Reducing musculoskeletal disorders among computer operators: comparison between ergonomics interventions at the workplace. Ergonomics 2012;55:1571-85.

65 Levanon Y, Gefen A, Lerman Y, et al. Multi dimensional system for evaluating preventive program for upper extremity disorders among computer operators. Work 2012;41(Suppl 1):669-75.

66 Mahmud N, Kenny DT, Md Zein R, et al. Ergonomic training reduces musculoskeletal disorders among office workers: results from the 6-month follow-up. Malays J Med Sci 2011;18:16-26.

67 Meijer EM, Sluiter JK, Frings-Dresen MH. Effectiveness of a feedback signal in a computer mouse on upper extremity musculoskeletal symptoms: a randomised controlled trial with an 8-month follow-up. Occup Environ Med 2009;66:305-11.

68 Mongini F, Ciccone G, Rota E, et al. Effectiveness of an educational and physical programme in reducing headache, neck and shoulder pain: a workplace controlled trial. Cephalalgia 2008;28:541-52.

69 Mongini F, Evangelista A, Rota E, et al. Further evidence of the positive effects of an educational and physical program on headache, neck and shoulder pain in a working community. J Headache Pain 2010;11:409-15.

70 Mongini F, Evangelista A, Rota $\mathrm{E}$, et al. Long-term benefits of an educational and physical program on headache, and neck and shoulder pain, in a working community. J Pain 2009;10:1138-45.

71 Parkkari J, Taanila H, Suni J, et al. Neuromuscular training with injury prevention counselling to decrease the risk of acute musculoskeletal injury in young men during military service: a population-based, randomised study. BMC Med 2011;9:35.

72 Rempel D, Lee DL, Dawson K, et al. The effects of periodontal curette handle weight and diameter on arm pain: a four-month randomized controlled trial. J Am Dent Assoc 2012;143:1105-13.

73 Robertson MM, Huang YH, O'Neill MJ, et al. Flexible workspace design and ergonomics training: impacts on the psychosocial work environment, musculoskeletal health, and work effectiveness among knowledge workers. Appl Ergon 2008:39:482-94.

74 Shiri $\mathrm{R}$, Martimo KP, Miranda $\mathrm{H}$, et al. The effect of workplace intervention on pain and sickness absence caused by upper-extremity musculoskeletal disorders. Scand J Work Environ Health 2011;37:120-8.

75 Spekle EM, Hoozemans MJ, Blatter BM, et al. Effectiveness of a questionnaire based intervention programme on the prevalence of arm, shoulder and neck symptoms, risk factors and sick leave in computer workers: a cluster randomised controlled trial in an occupational setting. BMC Musculoskelet Disord 2010;11:99.

76 van Eijsden-Besseling MD, Staal JB, van Attekum A, et al. No difference between postural exercises and strength and fitness exercises for early, non-specific, work-related upper limb disorders in visual display unit workers: a randomised trial. Aust J Physiother 2008;54:95-101.

77 Vermeulen SJ, Anema JR, Schellart AJ, et al. A participatory return-to-work intervention for temporary agency workers and unemployed workers sick-listed due to musculoskeletal disorders: results of a randomized controlled trial. J Occup Rehabil 2011;21:313-24.

78 von Thiele Schwarz U, Lindfors P, Lundberg U. Health-related effects of worksite interventions involving physical exercise and reduced workhours. Scand I Work Environ Health 2008:34:179-88.

79 Conlon CF, Krause N, Rempel DM. A randomised controlled trial evaluating an alternative mouse and forearm support on upper body discomfort and musculoskeletal disorders among engineers. Occup Environ Med 2008;65:311-18.

80 Lintula M, Nevala-Puranen N, Louhevaara V. Effects of Ergorest arm supports on muscle strain and wrist positions during the use of the mouse and keyboard in work with visual display units: a work site intervention. Int I Occup Saf Ergon 2001;7:103-16.

81 Galinsky T, Swanson N, Sauter S, et al. Supplementary breaks and stretching exercises for data entry operators: a follow-up field study. Am J Ind Med 2007:50:519-27.

82 Nevala-Puranen N, Pakarinen K, Louhevaara V. Ergonomic intervention on neck, shoulder and arm symptoms of newspaper employees in work with visual display units. Int J Ind Ergon 2003;31:1-10.

83 Faucett J, Garry M, Nadler D, et al. A test of two training interventions to prevent work-related musculoskeletal disorders of the upper extremity. Appl Ergon 2002;33:337-47.

84 Voerman GE, Sandsjo L, Vollenbroek-Hutten MM, et al. Effects of ambulant myofeedback training and ergonomic counselling in female computer workers with work-related neck-shoulder complaints: a randomized controlled trial. J Occup Rehabil 2007;17:137-52.

85 Peper E, Gibney KH, Wilson VE. Group training with healthy computing practices to prevent repetitive strain injury (RSI): a preliminary study. Appl Psychophysiol Biofeedback 2004:29:279-87.

86 Thomas RE, Vaidya SC, Herrick RT, et al. The effects of biofeedback on carpal tunnel syndrome. Ergonomics 1993;36:353-61.

87 Horneij $E$, Hemborg $B$, Jensen I, et al. No significant differences between intervention programmes on neck, shoulder and low back pain: a prospective randomized study among home-care personnel. J Rehabil Med 2001;33:170-6. 
88 Feuerstein M, Nicholas RA, Huang GD, et al. Job stress management and ergonomic intervention for work-related upper extremity symptoms. App/ Ergon 2004;35:565-74

89 Pillastrini $P$, Mugnai R, Farneti $C$, et al. Evaluation of two preventive interventions for reducing musculoskeletal complaints in operators of video display terminals. Phys Ther 2007:87:536-44.

90 Lin RT, Chan CC. Effectiveness of workstation design on reducing musculoskeletal risk factors and symptoms among semiconductor fabrication room workers. Int $J$ Ind Ergon 2007;37:35-42.

91 Rempel DM, Krause N, Goldberg R, et al. A randomised controlled trial evaluating the effects of two workstation interventions on upper body pain and incident musculoskeletal disorders among computer operators. Occup Environ Med 2006;63:300-6.

92 Rempel D, Tittiranonda P, Burastero S, et al. Effect of keyboard keyswitch design on hand pain. J Occup Environ Med 1999:41:111-19.

93 Lundblad I, Elert J, Gerdle B. Randomized controlled trial of physiotherapy and Feldenkrais interventions in female workers with neck-shoulder complaints. J Occup Rehabil 1999;9:179-94.

94 Rempel DM, Wang PC, Janowitz I, et al. A randomized controlled trial evaluating the effects of new task chairs on shoulder and neck pain among sewing machine operators: the Los Angeles garment study. Spine (Phila Pa 1976) 2007:32:931-8

95 Galinsky TL, Swanson NG, Sauter SL, et al. A field study of supplementary rest breaks for data-entry operators. Ergonomics 2000;43:622-38.

96 Mclean L, Tingley M, Scott RN, et al. Computer terminal work and the benefit of microbreaks. Appl Ergon 2001;32:225-37.

97 van den Heuvel SG, de Looze MP, Hildebrandt VH, et al. Effects of software programs stimulating regular breaks and exercises on work-related neck and upper-limb disorders. Scand J Work Environ Health 2003;29:106-16.

98 Kamwendo K, Linton SJ. A controlled study of the effect of neck school in medical secretaries. Scand J Rehabil Med 1991;23:143-52.

99 Luijsterburg PA, Bongers PM, de Vroome EM. A new bricklayers' method for use in the construction industry. Scand J Work Environ Health 2005;31:394-400.

100 Veiersted KB, Gould KS, Osteras N, et al. Effect of an intervention addressing working technique on the biomechanical load of the neck and shoulders among hairdressers. App/ Ergon 2008;39:183-90.

101 van der Molen HF, Grouwstra R, Kuijer PP, et al. Efficacy of adjusting working height and mechanizing of transport on physical work demands and local discomfort in construction work. Ergonomics 2004;47:772-83.
102 Fredriksson K, Bildt C, Hagg G, et al. The impact on musculoskeletal disorders of changing physical and psychosocial work environment conditions in the automobile industry. Int J Ind Ergon 2001;28:31-45.

103 Laing AC, Cole DC, Theberge N, et al. Effectiveness of a participatory ergonomics intervention in improving communication and psychosocial exposures. Ergonomics 2007;50:1092-109.

104 Ketola R, Toivonen R, Hakkanen M, et al. Effects of ergonomic intervention in work with video display units. Scand J Work Environ Health 2002;28: 18-24.

105 Gerr F, Marcus M, Monteilh C, et al. A randomised controlled trial of postural interventions for prevention of musculoskeletal symptoms among computer users. Occup Environ Med 2005;62:478-87.

106 Martin SA, Irvine JL, Fluharty K, et al. A comprehensive work injury prevention program with clerical and office workers: phase I. Work 2003;21:185-96.

107 Cook C, Burgess-Limerick R. The effect of forearm support on musculoskeletal discomfort during call centre work. App/ Ergon 2004;35:337-42.

108 Greene BL, DeJoy DM, Olejnik S. Effects of an active ergonomics training program on risk exposure, worker beliefs, and symptoms in computer users. Work 2005;24:41-52

109 Bohr PC. Efficacy of office ergonomics education. J Occup Rehabil 2000;10:243-55.

110 Tittiranonda P, Rempel D, Armstrong T, et al. Effect of four computer keyboards in computer users with upper extremity musculoskeletal disorders. Am J Ind Med 1999;35:647-61.

111 Leclerc A, Landre MF, Pietri F, et al. Evaluation of interventions for prevention of back, neck, and shoulder disorders in three occupational groups. Int I Occup Environ Health 1997;3:5-12.

112 Yassi A, Cooper JE, Tate RB, et al. A randomized controlled trial to prevent patient lift and transfer injuries of health care workers. Spine (Phila Pa 1976) 2001;26:1739-46.

113 Sackett DL, Rosenberg WM, Gray JA, et al. Evidence based medicine: what it is and what it isn't. BMJ 1996:312:71-2.

114 van Niekerk SM, Louw QA, Hillier S. The effectiveness of a chair intervention in the workplace to reduce musculoskeletal symptoms. A systematic review. BMC Musculoskelet Disord 2012;13:145

115 Rothmore P, Aylward P, Karnon J. Ergonomics and musculoskeletal injury prevention interventions in healthcare: are they worth it? Ergonomics Australia 2014;8:1. 